\title{
SISTEM INFORMASI RAWAT INAP PASIEN PADA RUMAH SAKIT BEDAH MITRA SEHAT DENGAN MENGGUNAKAN VISUAL BASIC
}

\author{
Kemal Farouq Mauladi ${ }^{1}$ \\ 1) Program Studi Teknik Informatika Fakultas Teknik Universitas Islam Lamongan \\ Email : kemalfarouq_mauladi@yaho.co.id
}

\begin{abstract}
ABSTRAK
Sistem informasi rawat inap pada rumah sakit bedah mitra sehat adalah salah satu jenis perangkat lunak yang dapat digunakan untuk membantu proses administrasi, pendaftaran serta pengolahan data pada salah satu instansi yang bergerak dalam bidang jasa pelayanan masyarakat. Dalam penelitian ini akan dibuat sebuah Sistem informasi rawat inap dengan menggunakan bahasa pemrograman Visual Basic.

Banyaknya data dan perlunya penyampaian informasi yang cepat dalam pelayanan administrasi pembayaran serta pendataan pasien dengan menggunakan teknologi informasi sebagai media yang dianggap mampu dan handal untuk membantu dalam pengolahan data dan penyajian informasi yang cepat, mudah dan akurat.
\end{abstract}

Kata Kunci : Sistem informasi, data dan informasi, data cepat dan akurat.

\begin{abstract}
Information system patient at hospital of healthy partner surgery is one kind of software that can be used to assist administration process, registration and data processing at one of institution which move in public service area. In this research will be made an inpatient information system using Visual Basic programming language.

The amount of data and the need for rapid information delivery in the administration of payment services and data collection of patients using information technology as a medium that is considered capable and reliable to assist in data processing and presentation of information fast, easy and accurate.
\end{abstract}

Keywords : Information systems, data and information, fast and accurate data.

\section{PENDAHULUAN}

Suatu instansi yang bergerak dalam bidang pelayanan manyarakat akan bekerja dengan baik apabila sarana dan prasarana yang ada dalam instansi tersebut dikelolah semaksimal mungkin. Instansi yang bergerak dalam bidang pelayanan masyarakat terutama pada rumah sakit khususnya dalam rumah sakit yang dikelola oleh pihak swasta.. pelayanan yang baik, cepat dan memuaskan merupakan kunci utama bagi perkembangan instansi tersebut. Salah satu instansi yang bergerak dalam bidang pelayanan masyarakat. Keberadaan rumah sakit sangatlah penting bagi masyarakat.Di era globalisasi ini komputerisasi sangatlah berguna selain untuk menyingkat watku dengan adanya komputerisasi ini para pegawai instansi juga dapat memasukkan data pasien secara tepat, cepat dan akurat.

Selama ini pendataan pasien masih dilakukan dengan cara manual walaupun datadata pasien tersebut sudah terinput dalam komputer tetapi untuk menghasilkan data yang kongkrit tentunya dibutuhkan suatu operator khusus untuk menangani masalah tersebut. Hal ini tentu membutuhkan hal yang lebih dalam menghasilkan data, terutama data yang membutuhkan spesifikasi tertentu, misal bulan dan tahun tertentu, selain itu dalam menyimpan dan mencari data memerlukan interval waktu yang cukup panjang. Untuk itu di perlukan suatu sistem yang cepat dan efisien 
guna meningkatkan kinerja dari instansi tersebut.

\section{Database Manajemen Sistem}

Sistem management database (Database Manajemen Sistem/DBMS) berisi tentang satu koleksi data atau sekumpulan data yang saling berelasi dan satu set program untuk mengakses data tersebut. Dengan kata lain system manajemen database terdiri dari database dan paket program pengelola untuk mengakses data, seperti menambah, menghapus, membaca dan memperbaiki/mengedit data.

\section{Aplikasi}

Aplikasi atau program aplikasi atau terkadang disebut program saja adalah sederetan kode yang digunakan untuk mengatur komputer agar melakukan sesuatu sesuai dengan keinginan yang membuatnya. Aplikasi dapat dibedakan menjadi aplikasi windows dan aplikasi konsol. Aplikasi windows adalah aplikasi yang berjalan pada windows. Aplikasi non-windows, misalnya yang berjalan pada dos, bias disebut aplikasi konsol Komponenkomponen yang digunakan dalam aplikasi Sistem Imrormasi rawat Inap.

\section{ANALISIS SISTEM}

Adapun gambaran dari proses Sistem Informasi Rawat Inap Pada Rumah Sakit Bedah Mitra Sehat ini dapat dicontohkan sebagai berikut: Jika ada pasien yang akan rawat inap tapi belum memiliki No.RM maka terlebih dahulu dia harus mendaftar sebagai pasien baru, tapi jika pasien tersebut sudah memiliki No.RM maka petugas loket tinggal mengentrikan data pasien yang harus dilengkapi. Selama pasien tersebut dirawat maka semua tindakan, obat, serta berapa lama pasien tersebut dirawat akan di imputkan dalam sistem informasi yang telah dibuat. Sehingga menghasilkan suatu laporan yang kongkrit dan apabila dikemudian hari pasien tersebut kontrol lagi maka catatan penyakit pasien tersebut masih ada dan dapat dilihat kembali.

\section{Kebutuhan Data}

Adapun data-data yang dibutuhkan dalam pembuatan sistem informasi ini antara lain:
1. Data pasien rawat inap pada puskesmas panceng

2. Obat yang tersedia di puskesmas tersebut

\section{Desain Sistem}

Proses 1: Data master, pada proses ini dibagi menjadi 2 proses, yaitu pasien dan entri obat. Pasien sendiri dibagi lagi menjadi 2 proses yaitu data pasien baru dan daftar pasien rawat inap. Data pasien baru digunakan untuk mencatat data-data pasien rawat inap yang belum memiliki No.RM. Sedangkan daftar pasien rawat inap digunakan untuk melengkapi data yang harus di isi bagi pasien yang sudah terdaftar atau sudah memiliki No.RM. Entri obat sendiri digunakan untuk mengentrikan atau memasukkan obat baru serta merubah Proses 2: Transaksi. Pada proses ini terdapat proses tagihan pembayaran, yang mana proses tersebut mencantumkan semua tagihan pasien yang harus dibayar. Lihat gambar 3.5

Proses 3: Laporan. Laporan akan dibagi lagi menjadi 2 proses yaitu laporan pasien dan laporan tagihan. Laporan ini didapat dari berapa banyakkah pasien yang pernah rawat inap pada rumah sakit bedah mitra sehat tersebut serta berapakah tagihan yang telah diterima. Laporan ini dapat dilihat berdasarkan bulan serta tahun tertentu sesuai dengan yang di inginkan.

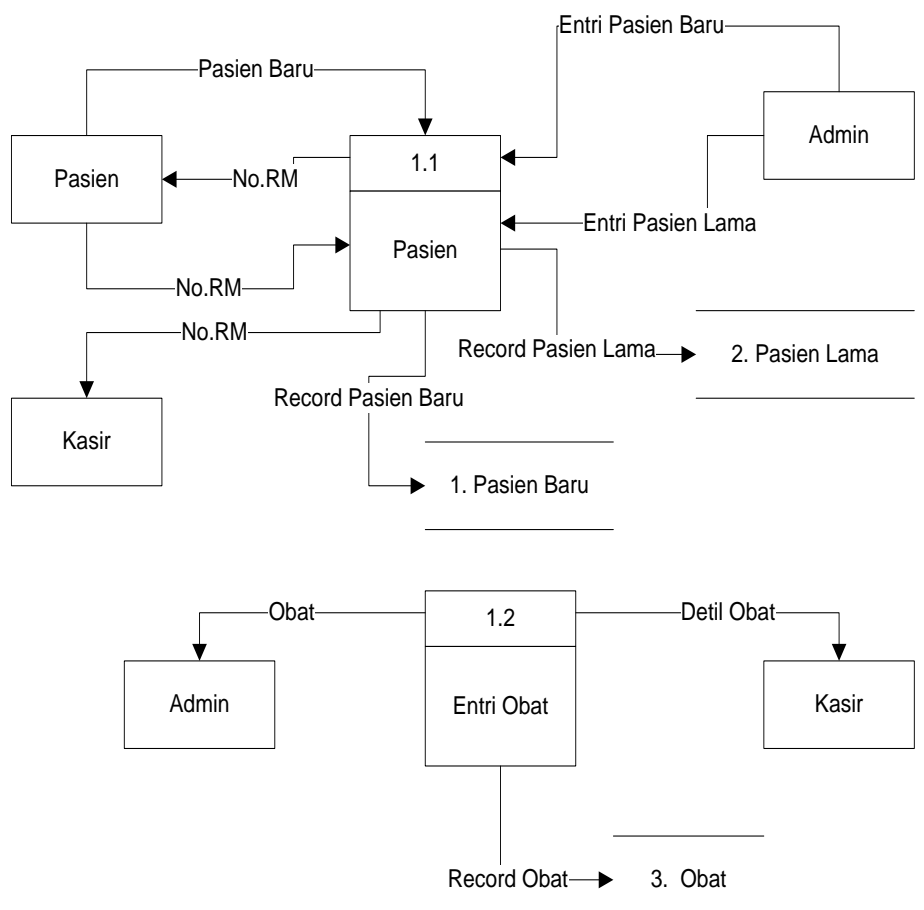

Gambar 1. Flow Diagram 


\section{PEMBAHASAN}

Suatu program aplikasi dibuat berdasarkan atas tujuan yang akan dicapai, dan untuk tujuan tersebut dibutuhkan beberapa tahapan yang harus dilalui. Oleh karena itu perlu kiranya dilakukan uji coba program, apakah dapat berfungsi dan bisa mencapai tujuan yang diharapkan.

Dalam pembuatan sistem informasi rawat inap pada rumah sakit bedah mitra sehat ini sedikitnya ada 8 contoh uji kasus sebagai berikut :

- Uji Kasus Pertama

Contoh kasus:

Mengimputkan data pasien baru kedalam database.

Langkah-langkah:

a.Login dan masuk kemenu utama kemudian pilih menu Data Pasien Baru maka akan muncul form Pendaftaran Pasien.

b.Klik tombol new maka form secara otomatis akan menjadi kosong.

c.Isikan data-data yang berhubungan dengan pasien seperti No.RM, Nama Pasien, Alamat, Jenis Kelamin, umur, Tanggal Lahir, Telfon.

d.Simpanlah data yang telah anda tuliskan dengan menekan tombol save

e.Data akan tersimpan dalam database dan dapat dilihat pada datagrid.

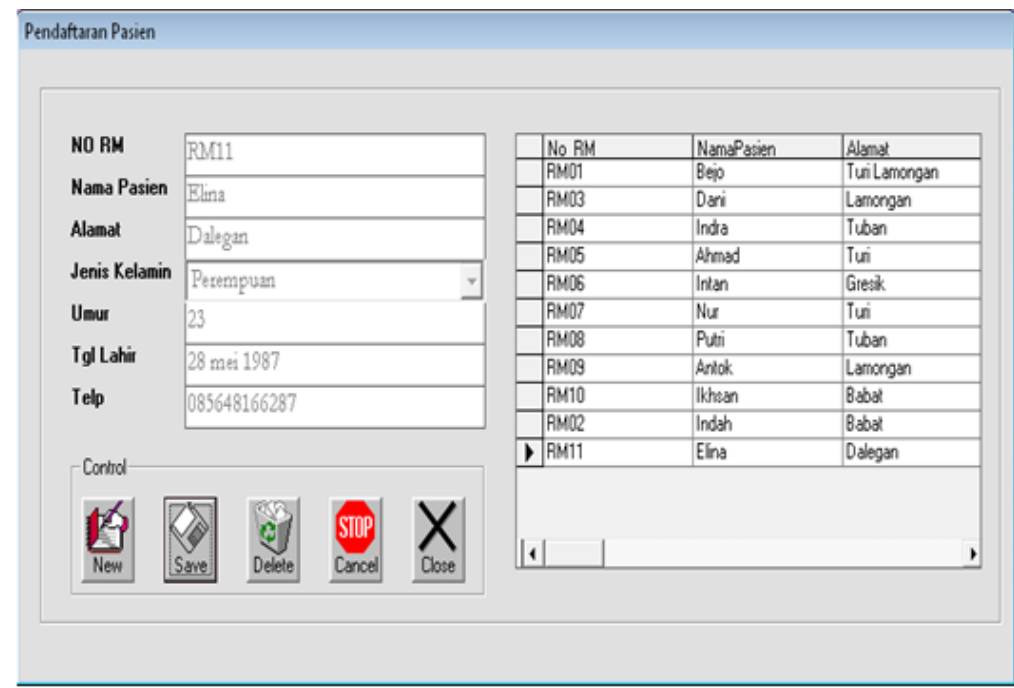

Gambar 3. Menu Entry Data Pasien

- Uji Kasus Ke-dua

Contoh Kasus:

Pasien yang mau rawat inap dan sudah memiliki No.RM akan langsung mengentrikan data baru buat rawat inap ke database.

Langkah-langkah:

a.Pilih menu data pasien rawat inap. Lihat

b.Isi cari berdasarkan No.RM kemudian tekan new untuk tambah baru, setelah itu isi semua data yang masih kosong, seperti Dokter, Diagnosa, Status, Spesialis, kemudian tekan save untuk menyimpan. Pada proses ini data akan di inputkan oleh petugas atau admin dalam pengisian data tersebut tidak boleh ada yang kosong ataupun kurang.

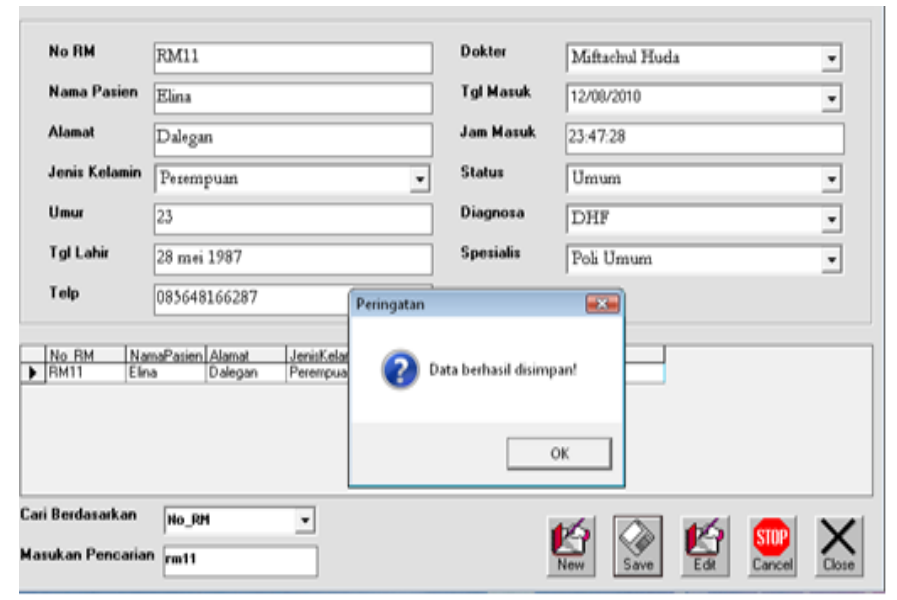

Gambar 4. Entry Data Rawat Inap pasien 
- Uji Kasus Ke-Tiga

Contoh kasus:

Terjadi kekeliruan penulisan data pasien rawat inap

Langkah-langkah:

a.Pilih menu data pasien rawat inap.

b.Pilih cari berdasarkan nama/No.RM kemudian isi pencarian yang akan dicari, kemudian tekan edit untuk merubah dan save untuk menyimpan.

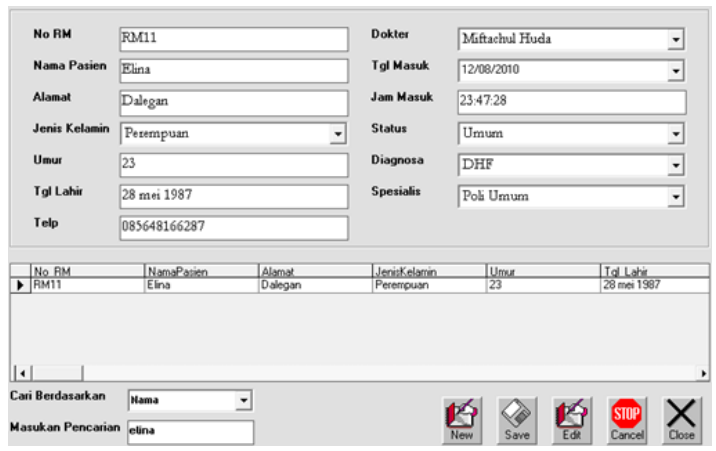

Gambar 5. Menu Data Rawat Inap edit Pasien

- Uji Kasus Ke-Empat

Contoh kasus:

Admin ingin menambah pasien dan mengedit data obat yang ada dengan Langkah-langkah:

a.Pilih menu Entriy Obat.

b. Klik new untuk menambah data obat baru, kemudian klik save untuk menyimpan.

c.Isi pilihan pada menu, kemudian isi kode atau nama obat yang ingin di edit. d.Klik edit untuk merubah dan save untuk menyimpan.

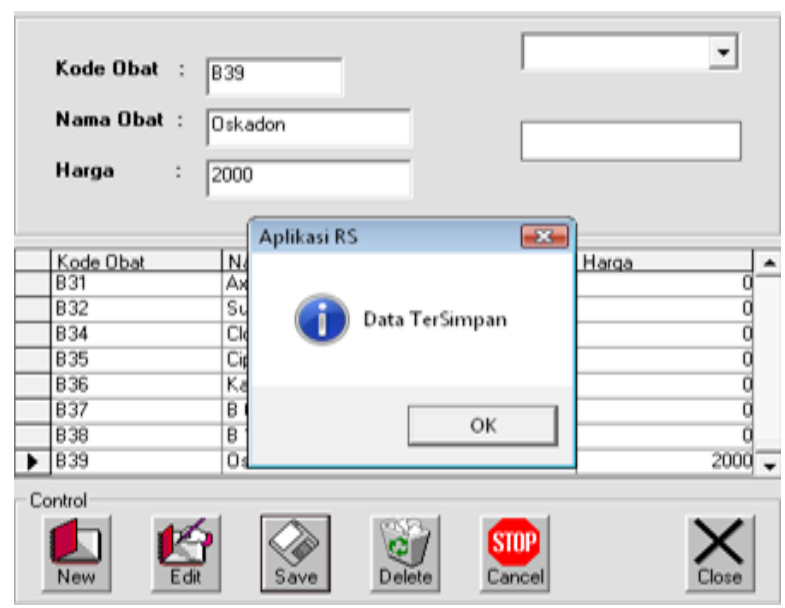

Gambar 6. Penambahan data obat
- UJI kasus Ke Lima

Contoh kasus:

Kepala rumah sakit bedah mitra sehat ingin melihat laporan pasien berdasarkan tahun dan bulan tertentu

Langkah-langkah:

a.Plih menu Laporan Pasien.

b.Isi tahun dan bulan yang ingin dilihat, kemudian tekan show laporan untuk melihat hasilnya.

\begin{tabular}{l} 
E. Laporan Pasien \\
Tahun \\
\hline
\end{tabular}

\section{Kesimpulan}

Gambar 7. Form Report

Kesimpulan dari seluruh pokok bahasan didalam penelitian ini mempunyai gambaran secara umum tentang analisa yang penulis adapun kesimpulanya sebagai berikut :

1.Mampercepat proses kerja karyawan dan memperlancar proses transaksi.

2.Dapat mengetahui berapa tagihan pasien yang harus dibayar dengan cepat, tepat dan efisien.

3.Dengan adanya Sistem Informasi ini dapat mempermudah kepala rumah sakit bedah mitra sehat dalam mengetahui hasil laporan yang di buat.

\section{Saran}

Setelah melihat serta dan menganalisa, maka penulis memberikan saran didalam melihat semua aktifitas yang managemen dimana kemanfaatan komputer khususnya terhadap proses pengoprasian sitem informasi rawat inap ini dapat dikatakan sudah sesuai dalam penerapanya dan akan lebih baik lagi apabila semua kegiatan didalam suatu usaha tersebut menggunakan sistem komputerisasi.

Dalam memaksimalkan kinerja dari suatu instansi, maka perlu diadakan penelitian pengoperasian komputer agar dapat meningkatkan kinerja para karyawan dalam instansi tersebut. 


\section{DAFTAR PUSTAKA}

Al Fatta, Hanif. 2007. Analisis dan Perancangan Sistem Informasi. Yogyakarta: Andi Offset.

Abdul Kadir, 2008. " Belajar Database menggunakan MySQL”. Yogyakarta: andi offset.

Hadi, Rahadian, 2002, "Pemrograman Windows API dengan Microsoft Visual Basic". Jakarta: PT. Elex Media Komputindo

Mulyanto, Agus, 2009, Sistem Informasi Konsep dan Aplikasi, Pustaka Pelajar, Yogyakarta.

Http://www.academia.edu/6158987/Konsep_D asar_SMS_Gateway_dan_Aplikasi MS_menggunakan_Visual_Basic_6_dan_FBU S_Lite.http://en.wikipedia.org wiki/short_Message_Service. (Diakses 2017) 
Jurnal Teknik A

Vol 9 No2 Septem ber 2017, 923-927

ISSN No. $2085-0859$

Halaman ini sengaja dikosongkan 